\section{HUMANASE SOCIAIS \\ V.8・N.2 • Agosto/Setembro/Outubro - 2019 \\ ISSN Digital: 2316-3801 \\ ISSN Impresso: 2316-3348 \\ DOI: $10.17564 / 2316-3801.2019 v 8 n 2 p 253-270$}
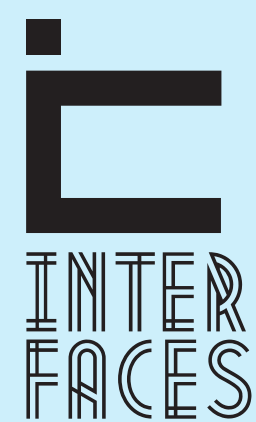

CIENTIFICAS

\title{
NA VOZ DE GONZAGA: A MUSICALIZAÇÃO DA MIGRAÇ̃̃O INTERNA E DA URBANIZAÇÃO BRASILEIRA
}

\section{THE INTERNAL MIGRATION AND BRAZLLIAN URBANIZATION BY GONZAGA'S SONGS}

ENLA VOZ DE GONZAGA: LA MUSICALIZACIÓN DE LA MIGRACIÓN INTERNA Y LA URBANIZACIÓN BRASLLEÑA

Monique Roecker Lazarin ${ }^{1}$

0 presente trabalho foi realizado com apoio da Coordenação de Aperfeiçoamento de Pessoal de Nível Superior - Brasil (CAPES) - Código de Financiamento 001.

\section{RESUMO}

0 presente trabalho tem por intuito entender 0 fenômeno da migração interna inter-regional da metade do século XX no Brasil, correlacionando-o à conjuntura de urbanização da época. Para tanto, utiliza como objeto a obra de Luiz Gonzaga, cantor que vivenciou tais processos e os registrou em seus cantos. Ou seja, o enfoque é o entendimento do fluxo migratório das áreas rurais do nordeste com destino às grandes cidades do sudeste a partir da análise de letras de músicas do Rei do Baião. 0 artigo parte da contextualização conjuntural do período em questão, juntamente como a revisão bibliográfica que embasa a reflexão do escrito. Em seguida, discorre sobre músicas selecionadas do repertório de Gonzaga, tendo como orientação o entendimento sobre o percurso migratório dos nordestinos em deslocamento. E, por fim, pondera-se sobre o que há além da trajetória, do movimento em si, concebendo as ressonâncias de tal fluxo interno mais contemporaneamente.

\section{PALAVRAS-CHAVE}

Migração interna. Migrações nordestinas. Urbanização. Luiz Gonzaga

\section{ABSTRACT}

This study aims to understand the phenomenon of internal inter-regional migration of the mid-twentieth century in Brazil, correlating it to the urbanization situation. For this, it is used as an analytical object the work of Luiz Gonzaga, a singer who experienced these processes and registered them in his songs. In other words, the focus is the understanding of migration from rural areas from the northeast to the lar- 
gest cities of the southeast, by the analysis of the letters of "Rei do Baião" songs. Thus, the article starts from a contextualization of the period in question, relating it to the bibliographical revision that bases the reflection of this writing. Then discusses the selected songs from the repertoire of Gonzaga, intending to understand this migratory route. Finally, in the endnotes, there is a consideration about what is beyond the movement itself, by designing the resonances of this internal flow more contemporaneously.

\section{KEYWORDS}

Internal Migration. Northeastern Migrations. Urbanization. Luiz Gonzaga

\section{RESUMEN}

El presente trabajo tiene como objetivo comprender el fenómeno de la migración interna interregional de mediados del siglo XX en Brasil, correlación con la coyuntura de la urbanización de la época. Para ello, utiliza el trabajo de Luiz Gonzaga, un cantante que experimentó tales procesos y los grabó en sus esquinas. En otras palabras, el enfoque es la comprensión del flujo migratorio de las zonas rurales en el noreste, destinado a las grandes ciudades del sureste a partir del análisis de las letras del "rey del baião". El artículo forma parte de la contextualización coyuntural del período en cuestión, junto con la revisión bibliográfica que basa el reflejo de la escritura. A continuación, habla de las canciones seleccionadas del repertorio de Gonzaga, con la orientación de entender la ruta migratoria del noreste desplazado. Y, finalmente, meditamos en lo que está más allá de la trayectoria, del propio movimiento, concibiendo las resonancias de tal flujo interno de manera más contemporánea.

\section{PALABRAS CLAVE}

Migración interna. Migraciones de Nordestina. Urbanización. Luiz Gonzaga

\section{INTRODUCÇÃO}

A confluência de três fenômenos - inter-relacionados - marcam muito fortemente meados da metade do século XX no Brasil: a mudança do sistema produtivo, a urbanização e as migrações internas. Isso porque o crescimento das cidades, em seu boom demográfico, está circunscrito num momento de urbanização no Brasil, motivado pela passagem da preponderância do sistema agrícola comunitário ao crescimento do capitalismo industrial e rural, se deu principalmente a partir da migração interna. Nesse fluxo interno às fronteiras do país, a população nordestina foi numérica e, mais ainda, simbolicamente muito representativa.

Assim, a questão a ser desenvolvida neste trabalho passa por entender essa conjuntura a partir da perspectiva da migração nordestina, utilizando como objeto de análise as músicas do repertório 
daquele que viveu esse fluxo e que o representou em sua arte: Luiz Gonzaga do Nascimento, o "Rei do baião". Ou seja, o presente artigo tem por objetivo compreender esse processo crucial à urbanização brasileira, tendo o enfoque no fluxo migratório das áreas rurais do Nordeste com destino às grandes cidades do sudeste, a partir da obra de Luiz Gonzaga.

Justifica-se a importância de tal estudo pelas seguintes questões, que serão explanadas mais detalhadamente em seguida: permite refletir o contexto e a forma que se deu a virada demográfica, da preponderância rural à urbana, no país; possibilita a crítica ao projeto de integração urbana de populações subalternas já naquele período, cuja não execução satisfatória ao decorrer dos anos levou ao "acumulo social do conflito" urbano; e, por fim, justifica-se a utilização da análise da produção artística, uma vez que se constitui em uma das formas de se conceber e representar o comum.

Posto isso, passa-se a análise das canções do repertório do cantor. Tais considerações são construídas em diálogo com o fundamento teórico primeiramente delineado sobre a conjuntura da qual Gonzaga pertence. A fim de estabelecer um fluxo concatenado de reflexão, considerando a amplitude e diversidade da obra, selecionou-se músicas que privilegiassem o entendimento sobre o percurso do movimento migratório ${ }^{4}$ em questão.

Por fim, nas notas finais, acrescenta-se algumas reflexões importantes com intuito de obter um olhar para além de um ponto final do percurso migratório: nas teorias migratórias classicamente conceituadas como fixação ou retorno. O olhar assim está direcionado para a migração como sendo mais que o deslocamento espaço-temporal em si, mas como fluxos que tem origens anteriores e consequências posteriores ao próprio movimento.

\section{CONTEXTO EMPÍRICO E O OLHAR TEÓRICO}

Primeiramente, a fim de aprofundar a análise contextual, há que se ressaltar que o olhar da pesquisa está posto sobre a relação entre o urbano e rural. 0 urbano tem muito de sua definição a partir do contraste com o que seria o rural; todavia, este trabalho não os concebe como pares opostos, que divide o Brasil em dois (DURHAM, 1973). De acordo com o proposto por Durham, aqui se entende que o urbano e o rural são dois sistemas integrados, no qual um é basilar ao outro. 0 contexto em questão justamente passa por entender como as grandes cidades vão se formando a partir do êxodo rural, numa relação demográfica inversamente proporcional uma a outra. Assim, mais do que aprofundar as dicotomias, pretende-se debruçar sobre uma obra que abordou as grandes migrações rurais nordestinas: pilar fundamental da formação das grandes capitais brasileiras, sobretudo do sudeste.

Dito isso, passa-se ao processo de urbanização propriamente dito. Para tanto, é imprescindível compreender o papel que as cidades ganharam no sistema capitalista. Esta frase revela que a cidade nem sempre significou e teve a mesma forma ${ }^{5}$, mas que desde o início da industrialização, ganhou dimen-

4 A ideia de utilizar o percurso migratório como recurso analítico provem do trabalho de Trindade (1995).

5 Lefebvre (2001, p. 78) aponta que a cidade passou por um desenvolvimento socio-histórico, da qual saiu de uma "cidade política”, passando pela "cidade comercial”, em seguida ganhando o caráter "industrial”. A partir daí ela encontra seu ponto crítico, calcado no duplo processo de industrialização e urbanização - ponto em que se situa atualmente. 
sões anteriormente inexistentes. Assim, segundo Lefebvre (2001), esse processo se deu a partir do sobreproduto do campo, acumulado - e transformado em dinheiro - nas cidades. Só com a acumulação de riquezas na cidade, afirma ainda o autor, se formou um processo com dois aspectos: a industrialização e urbanização; sendo o primeiro referente a produção econômica e o segundo à vida social.

Segundo Britto (2006), o primeiro surto industrial no país, entre o Segundo Império e República Velha, assim como a economia cafeeira, empregou estrangeiros; em sua maioria europeus, uma vez que sua vinda era financiada pelo Estado. Nesse contexto as capitais formam uma rede urbana incipiente, localizada principalmente no litoral do país, com concentração em São Paulo e Rio de Janeiro $^{6}$, cuja atividade estava na centralização dos serviços públicos, das atividades financeiras e comerciais da economia agrícola e na nascente industrialização. No entanto, não é datado desse período o acentuado processo de urbanização.

Britto (2006) afirma que a urbanização no Brasil é mais recente; mas, em contrapartida a países de capitalismo mais avançado, aqui o processo se deu com velocidade muito mais intensa e a partir do fluxo interno rural-urbano. Quanto aos números do crescimento das cidades, Durham (1973) levanta que se na década de 1920 somente cerca de 10\% da população era urbana, na década de 1940 esse número já havia saltado para 31\%, aumentando para 45\% em 1960 e se tornando maioria a partir da década de 1970 (56\%).

A intensificação da industrialização foi um dos motores. Contudo, e especialmente no Brasil, não deve ser tida como único agente da urbanização. Mesmo Lefebvre (2001), que fala de um contexto geográfico e social diferente, afirmou que na América Latina o processo de urbanização não pode ser unicamente relacionado à industrialização, pois esta não foi tão intensa quanto em outros lugares. Kowarick (1979), ao ponderar que grande parte dos imigrantes recorreram as atividades autônomas do setor terciário, corrobora com a ideia que a industrialização no país não foi tão intensa de modo a requerer e proporcionar a dimensão que se deu as migrações internas no país; a não ser como formação de mão de obra excedente disponível - motor do processo de espoliação urbana.

Aqui, a inserção do capitalismo no próprio ambiente rural foi decisivo aos movimentos de deslocamento em direção às cidades. Nesse caminho, o estudo de Durham (1973) se mostra como importante análise do contexto rural, abordando os três momentos da migração: as causas da migração, o processo de deslocamento e a nova situação do migrante. Para a autora, essas movimentações de população é um processo que se instaurou desde a década de 1930, momento em que o migrante nacional passa a ser substituto da mão de obra estrangeira no desenvolvimento econômico nacional. Mas, esse processo de transformação socioeconômico não atingiu somente as cidades, afetando também o campo: o modo de produção capitalista pôs em cheque o sistema produtivo rural tradicional.

Segundo Durham, as comunidades rurais tradicionais tinham como unidade produtiva a família e essa unidade se organizava em torno de grupos de vizinhança. Suas economias eram de subsistência, o que, de certa forma, as levavas a uma relativa autonomia - uma vez que estavam a margem do sistema produtivo do Brasil Colonial, desenvolvida principalmente com o uso de trabalho escravo. No entanto não eram autossuficientes, tais como grupos indígenas, devido à necessidade de instru-

6 Estas duas capitais concentravam mais de $50 \%$ do total da população morando em todas as capitais do país (BRITTO, 2006) 
mentos para sua atividade, bem como na dependência manifesta em relação ao acesso à terra. Essa marginalidade ao sistema agrícola hegemônico estabelecia uma relação de dominação que se dava tanto ao nível político quanto econômico.

Ainda assim, apesar de uma situação de pobreza, segundo a autora, esse sistema possuía uma certa estabilidade de produção para as necessidades socialmente definidas. Contudo, para manutenção de tal equilíbrio dois fatores são necessários: o acesso à terra e existência de um produto comerciável. Este produto seria o responsável pela monetarização que supriria a dependência externa (de instrumentos de trabalho), bem como responsável pelo incremento dos objetos de consumo, principalmente referente a alimentação (o que se tornava mais visado devido à expansão do mercado pela área rural e ao estreitamento do contato com as comunidades urbanas).

Paradoxalmente, afirma a autora, é justamente a possibilidade de produção de um produto comerciável que atraí a grande empresa rural, levando a incorporação de terras à grande propriedade. Justamente assim, através dessa incorporação, que se deu o crescimento da produção agrícola no Brasil, englobando o campo ao sistema produtivo nacional:

A expansão da grande lavoura representa a incorporação do território à economia monetária, ao sistema de mercado e sua integração na economia nacional. A terra se valoriza pelas suas potencialidades econômicas e a grande propriedade avança pelo território ocupado por posseiros e pequenos produtores independentes, despojando-os de seus meios de produção. (DURHAM, 1973, p. 97).

Assim se dá a proletarização do trabalhador rural, pois, despossado, passa a se constituir como mão de obra livre, enquanto o latifúndio passa a ter mão de obra assalariada e barata para a lavoura comercial. Ainda que superada a crise da posse, afirma a autora, aquele que obtêm pequenas terras entra na crise de produtividade, uma vez que não acessa as técnicas que the permita competir no mercado enquanto produtor independente. A emigração se mostra então como uma das poucas alternativas de melhoria de vida, como uma forma de aliviar as tensões econômicas e sociais. A mobilidade espacial é, então, um compulsório recurso adaptativo, em resposta a uma situação que não é excepcional: "a emigração aparece como resposta a condições normais de existência” (DURHAM, 1973, p. 113).

Apesar do tecido urbano estar em expansão devido às cidades de menor porte, os centros maiores são visados pela existência de um maior número de ofertas de trabalho. Essa mudança para as grandes cidades, segundo Durham, é a que provoca uma transformação aguda nos modos de vida dos imigrantes. Ou seja, ela não é simplesmente uma mudança geográfica; é, sobretudo, uma mudança no universo social - daí uma das maiores importâncias do estudo sociológico sobre as migrações.

Em suma, vê-se que entender mais sobre a migração interna é entender a reelaboração do sistema produtivo tanto na cidade quanto no campo. Esses movimentos, contudo, atravessam também as divisões e desigualdades regionais no país. Nesse sentido, a análise não é a de contraste entre uma região atrasada em comparação a uma moderna; é, em contrapartida, o entendimento - tal qual na relação campo e cidade - de que o próprio capitalismo gera essas relações desiguais, que são funcionais ao seu desenvolvimento no país (OLIVEIRA, 1977 apud SILVA; MENEZES, 2007). 
Ao pensar a emigração de determinadas regiões do país, especialmente de Minas Gerais e estados do Nordeste, Durham (1973) afirma que um dos principais alicerces desses deslocamentos está na procura de integração da população no sistema capitalista-industrial, deixando sistemas econômicos pouco produtivos. Assim, mesmo que as migrações dentro do próprio estado tenham sido numericamente maiores na chave do rural-urbano, analisar as inter-regionais - como o caso especificamente da região nordeste objeto do presente trabalho - se faz importante no tocante ao entendimento do porquê desses fluxos mais longínquos, que agregam mais a tonicidade regional.

E é nesse sentido que as migrações inter-regionais assumem especial relevância, embora, no conjunto, os movimentos de população dentro de um estado sejam numericamente muito mais importantes. É que elas representam o polo extremo de um processo através do qual a população das áreas menos favorecidas do país busca beneficiar-se do desenvolvimento econômico, transferindo-se para as regiões mais ricas onde concentram as oportunidades de melhoria de vida (DURHAM, 1973, p. 34).

Como vêm sendo enunciado, a problemática da integração econômica e social aparece como uma das grandes questões motivadoras das migrações internas, indo ao encontro do levantado por Silva (2016) sobre a importância do problema da integração na Sociologia. Na cidade, contudo, essa questão não se conclui tal como projetado pelos imigrantes; diversamente, se acirra enquanto conflito urbano. Esse acirramento do conflito dentro do contexto da expansão urbana foi teorizado por Kowarick (1979, p. 13) a partir de sua hipótese central:

[...] uma grande oferta de mão de obra constitui um elemento de importância para o sistema econômico realizar uma acumulação que tem se expandido, dilapidando boa parte da força de trabalho, principalmente os segmentos não qualificados que podem ser pronta e facilmente substituídos pela reserva de trabalho disponível.

O autor afirma, portanto, que o "milagre brasileiro" se realizou a partir da exploração da mão de obra, deteriorando a qualidade de vida dos trabalhadores. São Paulo, tido "como centro dinâmico do país", é um dos lócus da "desordenada" expansão urbana. Para Kowarick isso pode ser averiguado pela questão da moradia7: se nos primórdios da industrialização, até os anos de 1930, a questão

7 Na realidade, segundo Silva (2016), este enfoque habitacional foi central nas abordagens sobre a temática da integração das populações subalternas na cidade. Para Silva, existem 4 períodos nesta linha de estudo no Brasil: 1) Entre os anos 1950 e 1960, o enfoque estava na questão habitacional das favelas; 2) A partir da década de 1960, sob influência da teoria desenvolvimentista trabalhada na CEPAL, o olhar recai sobre a problema da integração urbana através da crítica da marginalidade ocasionada pelo mercado econômico global; 3) Nas décadas de 1970 e 1980, o foco de análise se direcionou aos movimentos sociais, como forma de oposição a dominação do Estado, e a favela torna-se então referência positivada por seu potencial de autonomia; 4) No cenário contemporâneo, devido ao aumento do conflito violento nas cidades, ocorre uma ruptura com as análises anteriores, uma vez que agora o conflito está fragmentado(não se pode pensar em termos de uma luta que é unificada, mesmo em última instância, pela questão de classe. Neste momento, afirma Silva, existe uma necessidade de construção de novas perspectivas teóricas e conceituais. 
habitacional era resolvida pelas fábricas, por meio da construção das Vilas Operárias ao seu redor, com a intensificação da industrialização cresce o número de trabalhadores e, consequentemente, a demanda por moradia; na mesma corrente eleva-se o preço dos terrenos e torna-se mais onerosa a construção das "vilas operárias". A empresa, então, transfere o custo da moradia e transporte para os trabalhadores e o de infraestruturas para o Estado.

Assim, a questão da moradia passa a ser definida nas "relações econômicas no mercado imobiliário" - nesse contexto surgem as periferias ${ }^{8}$ : uma forma de conseguir habitar a cidade, em meio a especulação imobiliária, com os baixos salários recebidos. 0 autor está a mostrar, assim, que essa espoliação urbana não é somente ocasionada pelas relações econômicas travadas no bojo do capitalismo na cidade, como é também um de seus motores, fazendo girar o mercado imobiliário: "torna-se favelado todo indivíduo ou família que não pode pagar o jogo especulativo do mercado imobiliário" (KOWARICK, 1979, p. 86). Neste estudo interessa especialmente o fato de que muitos dos imigrantes internos acabam por cair nessa rede espoliativa:

De forma majoritária, a favela abriga o trabalhador braçal que vende no mercado sua força de trabalho a preços irrisórios ou que, através de uma atividade autônoma, aufere rendimentos extremamente baixos. Dada a oferta de mão-de-obra existente na cidade, que continua a receber volumosos contingentes migratórios, os favelados encontram-se em desvantagem para competir por melhores remunerações no mercado de trabalho. (KOWARICK, 1979, p. 84).

A partir do supracitado argumento da não integração econômica e social de parcela significativa da população das cidades, elucida-se o fato de ser propriamente nesse contexto, a partir da década de 1950, em que Misse (2008) situa o início do acirramento do processo de "acumulação social da violência"9; desembocando, na atualidade, na dimensão que a questão da violência ganha na vida urbana.

Esse processo social da acumulação leva a efeitos perversos e preventivos: por um lado, a generalização da percepção da existência da violência difusa, da qual estaríamos sempre à mercê, levando ao sentimento de vitimização e de insegurança pública; por outro, leva a ativação de recursos de controle social (mecanismos acusatórios, demandas de criminalização e autoridade etc.) (MISSE, 1999, p. 41-42). Assim, o objeto de estudo do presente trabalho mostra-se significativo também enquanto perspectiva histórica para o entendimento da questão do conflito urbano, sobretudo em uma de suas gêneses.

\footnotetext{
8 Conceito "periferia" definido como: "aglomerados distantes dos centros, clandestinos ou não, carentes de infra-estrutura, onde passa a residir crescente quantidade de mão de obra necessária para fazer girar a maquinaria econômica” (KOWARICK, 1979, p. 31). 9 Importante frisar que Misse (2008, p.384) afirma que para entender a acumulação social da violência há que se "articular a sujeição criminal aos mercados ilegais nas áreas de pobreza urbana, às mercadorias políticas e à violenta repressão policial”. Além disso, vale ressaltar que além dos migrantes nordestinos, outros segmentos foram sofrendo seguidos processos de marginalização, que se somam no processo de acumulação social do conflito; em especial, para entender mais profundamente a questão é necessário também analisar a temática de classe-raça no país.
} 
Por fim, justifica-se a utilização das letras musicais vocalizadas por Luiz Gonzaga a partir de dois argumentos. O primeiro é o de não cair no determinismo estrutural que pode provir com uma análise macrossociológica; dando, em compensação, abertura a reflexão dos fluxos migratórios internos e a vida na cidade a partir da voz de um representante desses imigrantes:

Os migrantes rurais nordestinos não foram apenas reflexo de forças econômicas determinadas externamente, embora estivessem imersos nelas. Eles também foram agentes do seu próprio movimento e dessa forma, através de estratégias diversas, contribuíram na moldagem do processo migratório. (SILVA; MENEZES, 2007, p. 5).

O segundo argumento refere-se ao entendimento da arte enquanto criação imbuída, mesmo que de forma particular, no processo de inteligibilidade do comum, e, portanto, passível de ser estudada sociologicamente - de acordo com o conceito de partilha do sensível de Rancière (2009, p.15):

[...] sistema de evidências sensíveis que revela, ao mesmo tempo, a existência de um 'comum' e dos recortes que nele definem lugares e partes respectivas. Uma partilha do sensível fixa portanto, ao mesmo tempo, um comum partilhado e partes exclusivas. Essa repartição das partes e dos lugares se funda numa partilha dos espaços, tempos e tipos de atividades que determina propriamente a maneira como um comum se presta à participação e como uns e outros tomam parte nessa partilha.

A partir desse entendimento, o autor propõe que uma sociedade organizada está dividida de forma em que as atividades estão segmentadas, por uma impossibilidade de fazer "outra coisa", fundamentada na ausência de tempo. Assim, a constituição do mundo sensível comum se dá na imbricação da pluralidade das atividades humanas. Porém, a arte perturba essa partilha, uma vez que seu trabalho sai do confinamento do particularismo das atividades, e se reterritorializa no espaço de discussão pública. 0 princípio da ficção tenta estabilizar essa visibilidade deslocada; no entanto, a arte, enfatiza Rancière (2009), é uma técnica e não uma mentira. As práticas artísticas não são uma exceção às outras práticas, mas produzem representação ao mesmo tempo em que reconfiguram as partilhas do comum.

\section{NA VOZ DE GONZAGA: O PERCURSO MIGRATÓRIO}

É possível pensar, a partir de Gonzaga, as migrações internas e a urbanização no Brasil uma vez que ele mesmo vivenciou, de certa forma, esse fluxo do desenvolvimentismo. Nascido em 1912 em Exu, interior de Pernambuco, após servir ao exército por diversos estados do país, em 1939 foi parar na cidade do Rio de Janeiro, na busca de viver enquanto músico. De início seu repertório era composto por ritmos da moda na época, como valsa, choro e tango; o regionalismo musical que the 
fez ganhar sucesso só se tornou seu foco a partir dos anos $40^{10}$ : o baião passa então a ser seu ritmo característico, complementado por outros como o xaxado e o xote.

As vestimentas, primeiramente focadas na figura do cangaceiro e depois do vaqueiro, também foram adotadas no reforço à estética nordestina. Nesse caminho, grandes parcerias foram importantes para que o sanfoneiro fizesse sucesso cantando "as coisas do sertão", em destaque Humberto Teixeira ${ }^{11}$ e Zé Dantas ${ }^{12}$. Observa-se, então, uma construção simbólica regional, pautada sobretudo na representação estética do homem sertanejo (RISÉRIO,1990), que vai sendo edificada na obra do "Rei do Baião".

Essa construção não por acaso se dá em diáspora: é o choque de alteridade que faz se atentar a identidade (SAYAD, 1998). Afinal, a identidade, como afirmado por Sovik (2003, p. 15-16) em concordância com Hall: "é um lugar que se assume, uma costura de posição e contexto e não uma essência ou substância a ser examinada”. Entende-se, doravante, a conexão da simultaneidade do sucesso do sanfoneiro com a intensificação das migrações nordestinas para as capitais do sudeste, ambos se acentuando a partir da década de 1940. Ele se tornou figura representativa de uma população em deslocamento, cantando a saudade do seu sertão em meio a vida nas grandes cidades - salientando que a emigração e a imigração são lados contrários do mesmo fluxo (SAYAD, 1998).

Para entender mais do significado desses processos por quem o vivenciou, as letras de Gonzaga se mostram como importante recurso analítico. Sendo assim, para este trabalho selecionou-se três músicas que tocam diretamente a temática: “Asa Branca”, “Cidadão" e "A triste partida”. Nelas buscou-se compreender o "percurso migratório” (TRINDADE, 1995) ${ }^{13}$ das trajetórias migrantes por ele cantadas.

Antes das análises, sublinha-se, porém, que não é qualquer migração nordestina o enfoque de sua obra: é a do interior da região do Nordeste, do sertão, em que predomina as pequenas propriedades, com foco na economia de subsistência, e onde a seca se faz mais ardida ${ }^{14}$. Importante destacar ainda que apesar das letras com narrativa de sofrimento, a estética das músicas de Gonzaga não se reduz a lamentação: são sobretudo de um ritmo dançante. Assim, denunciar a seca, a desigualdade, a difícil vida dos imigrantes na cidade e as discrepâncias regionais não pressupõem a uma abordagem pela vitimização, tampouco é o que se pretende realizar aqui.

10 No documentário "Luiz Gonzaga: a luz do sertão" (1999), foi a instigação de alguns estudantes cearenses, que assistiam a umas das suas apresentações, para que Gonzaga tocasse músicas da sua terra que lhe reorientou a esse caminho sonoro.

11 Considerado o “Doutor do Baião”, Humberto Teixeira era cearense, mas ainda adolescente foi morar no Rio de Janeiro. Foi o primeiro parceiro de Gonzaga, quando foram lançados grandes sucessos, como “Asa Branca”, “Baião”, "Juazeiro" e "Respeita Januário”. Ver mais no documentário “O Homem que engarrafava nuvens”, de Lírio Ferreira (2009).

12 Gonzaga conheceu Zé Dantas no final da década de 1940, um pernambucano com quem escreveu canções como "Xote das meninas", "Vem, morena" e "A volta da Asa Branca".

13 Para Trindade esse percurso é composto primeiramente pela intenção de partir, seguido pelos preparativos da partida, viagem, primeira instalação, inserção e, por fim, fixação ou retorno. Aqui não se limitou especificadamente e separadamente cada etapa, mas o olhar permeou o entendimento geral de tal trajetória.

14 Risério (1990) relembra da importância de não simplificar o Nordeste, que poderia, ser subdivido em ao menos três: a área litorânea, o agreste e o sertão. 
Das motivações de partir: condições socioecológicas de sua região aparecem constantemente como causa da decisão de emigrar. Na música "Asa Branca” é narrado que "até mesmo a Asa branca bateu asas do sertão", onde a terra se faz arder como fogueira de São João, não deixando vingar a plantação e sobreviver os animais. O mesmo compõe a letra de "A triste Partida": passam-se vários meses de seca, de Setembro a Março, e "o nortista”, por mais que rogue a Deus, não vê cair a água capaz de fazer passar seu "medo da peste da fome feroz" - assim, se delineia a intenção de ir para São Paulo:

Agora pensando Ele segue outra tría Chamando a famía

Começa a dizer (Meu Deus, meu Deus)

Eu vendo meu burro Meu jegue e o cavalo Nós vamo à São Paulo Viver ou morrer

Aqui ressalta-se a relação das letras com o que foi teorizado por Durham. Segundo a autora, "o homem do campo é objeto de tensões cada vez maiores, ante as quais a emigração se apresenta como uma das poucas soluções possíveis" (DURHAM, 1973, p. 111). Tais pressões, emanadas da sociedade global, trazem motivações construídas dentro do âmbito individual para migrar. Assim, dentre as atribuições mais comuns à decisão de mudança está a de "melhorar a qualidade de vida”. A autora considera que a motivação não está pautada num evento específico, numa situação anormal; ao contrário, se dá quando percebe que a situação desfavorável em que se encontra é permanente.

Essa condição precária infindável do homem pobre da área rural, afirma Durham, está atrelada a miséria, ao trabalho duro, a incerteza da produção. É a partir dessa reflexão que a autora propõe a mobilidade espacial como "um recurso adaptativo na economia de subsistência”. No caso específico cantado por Gonzaga, existe a intensidade da seca: por mais que se espere ela passar, um momento o migrante percebe que essa situação não é transitória; com os recursos que possui, a sua única expectativa de consegui permanecer era a chuva. Sem uma alternativa, vende suas posses para financiar a ida para a grande cidade.

Pois logo aparece

Feliz fazendeiro

Por pouco dinheiro Lhe compra o que tem

Desessencializa-se, assim, a seca: ela impõe severas dificuldades à subsistência, mas não é empecilho total à produção, pois há quem possua capital suficiente para conseguir amenizar tais entra- 
ves $^{15}$. A desigualdade social nas áreas rurais fica, então, em evidência; e entrelaça-se com as condições climáticas nas motivações para partir.

Ao seguir por "A Triste Partida" analisa-se a centralidade da família tanto no contexto regional quanto no processo migratório. Fundamental recordar que em áreas rurais de pequeno porte, a família se mostra como unidade produtiva e, seguindo nessa influência, entende-se que também a migração é um projeto familiar (DURHAM, 1973). Mesmo em "Asa Branca”, em que o personagem se desloca sozinho, a relação com a mulher amada está posto no fluxo: ele voltará assim que florescer a plantação. A separação no deslocamento não infere ruptura dos laços familiares; se mostra, em contrapartida, como uma tentativa de contornar as dificuldades da vida, já que nem sempre se tem os recursos suficientes para bancar a mudança de todos - nesses casos, em geral, quem migra é o homem. As relações de gênero são estruturantes não somente dentro das vidas na comunidade como às relações em fluxo espacial.

E por que o destino escolhido é a metrópole? Segundo Britto (2006), a industrialização acentuou as desigualdades regionais, propulsando tais deslocamentos:

A grande concentração espacial do desenvolvimento da economia brasileira, comandada pelo processo de industrialização no Rio de Janeiro e, principalmente, em São Paulo, ampliou os desequilíbrios regionais e sociais, impulsionando as migrações internas, que transferiram a população do campo para a cidade, assim como redistribuíram entre os estados e entre as diferentes regiões do Brasil. (BRITTO, 2006, p. 224).

Segundo Silva e Menezes (2007) a imigração não é somente uma resposta às necessidades materiais, como também as de manter as ilusões vivas, de acreditar numa possibilidade de melhoria, de ascensão social. São Paulo, a capital financeira, aparecia como o centro das oportunidades; o que Kowarick (1979, p. 49) relacionou com a venda do "mercado de ilusões", na qual a cultura de massas tem papel importantíssimo: "é o mundo das vitrines, da televisão, dos painéis publicitários onde os que subiram servem de exemplo e esperança para aqueles que só podem consumir na fantasia o sucesso do estilo de vida daqueles que venceram".

Chegaram em São Paulo

Sem cobre quebrado

E o pobre acanhado

Percura um patrão

(Meu Deus, meu Deus)

Só vê cara estranha

De estranha gente

Tudo é diferente

Do caro torrão

15 Lembrando que, como dito anteriormente, se trata de um período de expansão do capitalismo inclusive nas zonais rurais do Brasil, ganhando ainda mais espaço as grandes propriedades. 
Este trecho de "A Triste Partida" fala do estranhamento primeiro com a vida das grandes cidades. Segundo Durham (1973) este é o processo que marca fortemente a diferença interna aos fluxos migratórios rurais-urbanos: se deslocar para cidades menores não implica mudanças tão bruscas nos padrões de sociabilidade quanto ir para uma grande cidade ${ }^{16}$. Não obstante, nas músicas cantadas por Gonzaga, o lamento não decorre somente do choque cultural, como também é formado pela não concretização da melhoria de vida pela via econômica; é o mercado de ilusões, que motivara a imigração, desvelando-se.

Só vive devendo

E assim vai sofrendo

É sofrer sem parar

(A TRISTE PARTIDA)

A música de Gonzaga aprofunda esse debate com a música “Cidadão”. Nela não se diz se o narradorprotagonista do enredo da canção é especificamente um imigrante; mas aproxima-se a temática por Gonzaga cantar as coisas do seu povo e saber que a construção civil foi um dos grandes recrutadores da mão de obra dos imigrantes internos. Ela começa abordando a questão da vivência nas periferias, que impunha dificuldades ao trabalho:

Tá vendo aquele edifício moço

Ajudei a levantar

Foi um tempo de aflição

Eram quatro condução

Duas prá ir, duas prá voltar

O estudo de Kowarick (1979) emerge novamente em correspondência para pensar a relação entre o surgimento da periferia e uma forma espoliativa de apropriação do trabalho. Isso segue acirrando-se na música em questão, já que o trabalhador não só não consegue viver nos bairros em que trabalha, como também não pode acessar os edifícios que construiu.

Hoje depois dele pronto Olho prá cima e fico tonto Mas me vem um cidadão

E me diz desconfiado

"Tu tá aí admirado?

Ou tá querendo roubar?»

16 Uma das obras clássicas que abordam essa sociabilidade singular das grandes cidades, em confronto com a vida no campo, é "As grandes cidades e a vida do espírito". Nela Simmel aponta que nas grandes cidades - como resposta, proteção, à "intensificação da vida nervosa" - ocorre uma sobreposição cada vez maior do espírito objetivo ao subjetivo, levando a uma existência pessoal mais individualizante. 
Este trecho faz recordar do conceito de sujeição criminal de Misse (2008), abordando a existência de um criminoso anterior ao crime: um assujeitamento ao crime. Não é o crime em si que importa, a questão está deslocada ao processo de incriminalização, de indicar o sujeito "propenso ao crime", e isto é feito a partir da estigmatização de um tipo social ${ }^{17}$.

Ainda é possível remontar a Bourdieu (2008): o espaço social em que se situa um agente se traduz, mesmo que de maneira confusa, em seu espaço físico. Nesse sentido, o autor, está pensando na localização relacional a outros agentes. Mas, complexifica o entendimento ao associar a ideia de capital social: assim, aproximação no espaço físico não necessariamente significa aproximação social, se não se possui os recursos - o hábito - exigidos para tal integração. 0 "ocupar fisicamente um habitat sem habitá-lo" é o que ocorre no trecho da música supracitado.

Daí o choque do "cidadão" que não entende o que ele está fazendo ali parado, observando o prédio, afinal, não se é esperado que ele esteja ali nessa situação. 0 esperado é o que Bourdieu nomeou de "espaço social reificado", que o sujeito habite o espaço físico considerado condizente com seu lugar social: no caso dos migrantes nordestinos de baixa renda, as periferias.

Em “A Triste Partida” Gonzaga canta projetos de vida via migração que não deram certo:

Faz pena o nortista Tão forte, tão bravo Viver como escravo

No norte e no sul (Ai, ai, ai, ai)

A alternativa econômica que era esperada encontrar em São Paulo foi ilusória. Importante destacar que a figura do Estado, enquanto possível agente garantidor da mínima qualidade de vida, não aparece - a integração esperada é via trabalho, não se concebendo ainda a ideia de sujeito de direitos. Interessa, deste trecho, igualmente notar a significação bipolarizada do Brasil: o imigrante desta música se deslocou especificamente para São Paulo, ou seja, sudeste.

Assim, os termos refletem a unificação das regiões em duas, cuja polaridade se dá por meio do contraste: o norte x o sul. Se pode-se unificar e dividir o país em dois, isso é devido a alusão às categorias classificatórias que também punham um olhar binário sobre o Brasil, a exemplo das comparações valorativas rural-urbano e desenvolvido-subdesenvolvido. A ironia está que a antítese esperada, que contrastaria as regiões, unificou-se no quesito qualidade de vida deste imigrante.

Em síntese, percebe-se que as etapas do percurso migratório composto pela instalação e inserção não se dão da forma esperada. A próxima fase seria, então, a fixação ou o retorno. Em "A triste partida” o retorno não é possível pois na cidade grande "vive preso", “devendo ao patrão”; ou seja, não tem

17 Estigmatização essa que não se dá só ao nível de rotulação: ela também age na própria subjetividade, fazendo com que o sujeito a internalize. Além disso, diferente da teoria da rotulação interacionista, Misse afirma que não é preciso que aja o ato concreto para a estigmatização. Assim, a sujeição criminal refere-se mais do que um processo de discriminação, refere-se a um fator determinante na acumulação social do conflito: "Eu o temo, por isso o persigo - não se trata apenas de estigma ou preconceito, nem de rótulo, mas de riscos, regras de experiência, conflito." (MISSE, 2012, p. 208). 
os recursos financeiros para tal. Mas, seja nesta música, seja em “Asa Branca”, o ideal do retorno se canta o tempo todo. Assim, se o retorno não se faz possível, tampouco pode-se falar em fixação.

\section{NOTAS FINAIS}

A análise do repertório de Luiz Gonzaga à luz da problemática da urbanização via migração interna no país reporta a um processo social intenso ocorrido principalmente entre as décadas de 1940 e 1970, no qual destaca-se o deslocamento da população do interior nordestino para as grandes capitais do sudeste. Contudo, tanto pela bibliografia, quanto pelas letras estudadas, verificou-se que se emigração tinha por intuito uma melhoria nas qualidades de vida e integração nesse novo ideal urbanizado; todavia, a imigração não se deu da forma esperada. Pode-se refletir isso a partir dos dois principais caminhos daí seguidos: o conflito urbano e a migração de retorno.

Viu-se, pensando na perspectiva da cidade, que a incorporação desses imigrantes na metrópole se deu de forma espoliativa: explorando-se sua mão de obra, marginalizando suas habitações e sem integração social. Assim, já naquele período, via letras do Gonzaga, viu-se a sujeição criminal ocorrer, demonstrando que o conflito urbano insurge. Essa promessa de integração nunca realizada - em conjunto com outros processos de marginalização de outros segmentos da população, em destaque para a questão racial - acirra-se em violência com o passar dos tempos.

Por outra via, observa-se a não satisfação esperada dos imigrantes nordestinos nas capitais do sudeste pela intensificação contemporânea da migração de retorno (BAENINGER, 2012), justamente no eixo sudeste-nordeste. Essa continuidade do fluxo coloca então em questão os conceitos. Como foi visto, a fixação, por mais que os imigrantes nordestinos cantados por Gonzaga permanecessem na grande cidade, era a alternativa que tinham por hora, não significando o fim de novos planos; assim, o conceito não dava conta de abarcar o complexo significado do permanecer - afinal, de acordo com Giddens (1989), "não ter escolha” não denota que a ação tenha sido convertida em reação.

No intuito de aprimorar isso, Baeninger propõe pensarmos conceitos que contemplem a reversibilidade das migrações internas, refletindo em termos de "circuitos migratórios", que, mais que composto por uma origem e um destino fixo, é influenciado por áreas de atração, retenção ou expulsão, variáveis dependentes das influências do contexto - local e global.

Em suma, a ideia central é de que a análise das letras do repertório de Luiz Gonzaga possibilita compreender o deslocamento do rural ao urbano a partir da perspectiva do nordestino, privilegiando o entendimento sobre o percurso imigratório em questão. Mas, pensar isso contemporaneamente permite ainda refletir a conjuntura do período em questão, como também suas consequências e influências na conjuntura atual. A migração interna nordestina da metade do século XX, como demonstrado, tem suas raízes num processo de inserção do capitalismo no país, que torna ainda mais difícil a produtividade dos pequenos agricultores no sertão.

$\mathrm{Na}$ cidade, todavia, a jornada destes migrantes, em geral, continua às margens do sistema produtivo; e essa não integração, no cenário urbano atual, pode ser relacionada como mais um dos pontos 
relevantes no acirramento do conflito social. Também merece ser destacada a estratégia de retorno a essa não conformação da vida nas grandes metrópoles. Ou seja: isso reflete que a migração, enquanto fenômeno social, tem seus efeitos para além da trajetória individual ou grupal - do percurso em si. Por isso pensar os fluxos cantados por Gonzaga ainda hoje se faz importante: é falar da conjuntura anterior às migrações, dos próprios deslocamentos, e traçar suas implicações posteriores.

\section{REFERÊNCIAS}

BAENINGER, Rosana et al. Rotatividade migratória: um novo olhar para as migrações internas no Brasil. REMHU: Revista Interdisciplinar da Mobilidade Humana, 2012. Disponível em: http://www. scielo.br/pdf/remhu/v20n39/v20n39a05. Acessado em: 17 mar. 2018.

BOURDIEU, Pierre. Efeitos de lugar. In: BOURDIEU, Pierre (Org.). A miséria do mundo. Petrópolis: Editora Vozes, 2008. p. 159-166.

BRITO, Fausto. O deslocamento da população brasileira para as metrópoles. Estudos Avançados, v. 20, n. 57, p. 221-236, 2006. Disponível em: http://www.scielo.br/scielo.php?script=sci_arttext\&pid =S0103-40142006000200017. Acessado em: 17 mar. 2018.

DURHAM, Eunice. A caminho da cidade: a vida rural e a migração para São Paulo. São Paulo: Perspectiva,1973.

GIDDENS, Anthony. A constituição da sociedade. São Paulo: Martins Fontes, 1989.

KOWARICK, Lúcio. A espoliação urbana. Rio de Janeiro: Editora Paz e Terra, 1979.

LEFEBVRE, Henri; FORTUNA, Carlos. 0 direito à cidade. São Paulo: Centauro, 2001.

MISSE, Michel. Malandros, marginais e vagabundos \& a acumulação social da violência no Rio de Janeiro. 1999. Tese (Doutorado em Sociologia) - Programa de Pós-Graduação em Sociologia, Instituto Universitário de Pesquisas do Rio de Janeiro (IUPERJ), Universidade Cândido Mendes, Rio de Janeiro, 1999.

MISSE, Michel. Sobre a acumulação social da violência no Rio de Janeiro. Civitas: Revista de Ciências Sociais, v. 8, n. 3, p. 371-385, 2008. Disponível em: http://revistaseletronicas.pucrs.br/ojs/ index.php/civitas/article/viewFile/4865/3641. Acessado em: 17 mar. 2018.

MISSE, Michel. Sujeição criminal. In.: LIMA, Renato Sérgio de; RATTON, José Luiz; AZEVEDO, Rodrigo Ghiringhelli (Org.). Crime, polícia e justiça social no Brasil. São Paulo: Contexto, 2014. 
OLIVEIRA, F. A economia brasileira: crítica à razão dualista. Seleções Cebrap 1, 3. ed., 1977.

RANCIÈRE, Jacques. A partilha do sensível. 34. ed. São Paulo: EXO experimental org., 2009.

RISÉRIO, Antonio. O solo da sanfona: contextos do rei do baião. Revista USP, n. 4, p. 35-40, 1990. Disponível em: http://www.revistas.usp.br/revusp/article/view/25502. Acessado em: 17 mar. 2018.

SAYAD, Abdelmalek. A imigração ou os paradoxos da identidade. São Paulo: Edusp, 1998.

SILVA, M. A. M.; MENEZES, M. A. Migrações rurais no Brasil: velhas e novas questões.

Revista Eletrônica do Nead, Brasília/DF, v. 1, p. 1-14, 2007. Disponível em: http://www. faed.udesc.br/arquivos/id_submenu/1416/migracoes_rurais_no_brasil_velhas_e_ novas_questoes.pdf. Acesso em: 17 mar. 2018.

SILVA, Luiz Antonio Machado da. Fazendo a cidade: trabalho, moradia e vida local entre as camadas populares urbanas. Rio de Janeiro: Mórula, 2016.

SIMMEL, Georg. As grandes cidades e a vida do espírito (1903). Mana, v. 11, n. 2, p. 577-591, 2005. Disponível em: http://www.scielo.br/scielo.php?script=sci_arttext\&pid =S0104-93132005000200010. Acessado em: 17 mar. 2018.

SOVIK, Liv. Apresentação: para ler Stuart hall. In: HALL, S. Da diáspora: identidades e mediações culturais. Tradução de Adelaine La Guardiã Resende et al. Belo Horizonte: UFMG, 2003.

TRINDADE, Maria Beatriz Rocha. Sociologia das migrações. Lisboa: Universidade Aberta, 1995. 


\section{(). (1) (2)}

Este artigo é licenciado na modalidade acesso abertosob a Atribuição-Compartilhalgual CC BY-SA

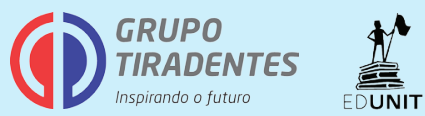


